
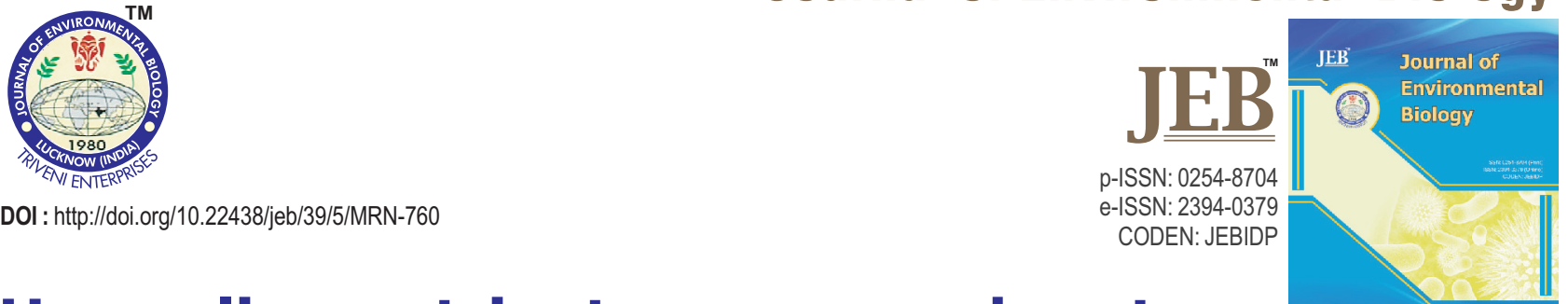

\title{
Up-scaling nutrient, energy and system productivity of pigeonpea-wheat cropping system in Indo-Gangetic plains of India
}

Authors Info

U. Singh ${ }^{1 *}$, C.S. Praharaj', S.S. Singh', K.K. Hazra and N. Kumar'

'Division of Crop Production, ICAR-Indian Institute of

Pulses Research,

Kanpur-208 024, India

${ }^{2}$ ICAR-Agricultural Technology Application Research Institute, Kolkata-700 097, India

${ }^{3}$ Agricultural and Food Engineering Department, Indian Institute of Technology Kharagpur-721 302, India

${ }^{*}$ Corresponding Author Email : singhummed@yahoo.co.in

Key words

Cropping system

Energy efficiency

Nutrient acquisition

Pigeonpea

Wheat

\section{Publication Info}

Paper received : 29.12 .2017

Revised received : 20.01.2018

Re-revised received : 24.02 .2018

Accepted : 05.03.2018

\section{Abstract}

Aim : The major impediments in realizing the potential productivity of pigeonpea-wheat rotation in IndoGangetic plains includes lack of short-duration pigeonpea cultivar ( $<120$ days), suboptimal plant stand in pigeonpea and substantial yield loss of wheat following delayed sowing. In view of the above issues, the present study aimed to assess the potential of tillage-based crop establishment practices and appropriate cultivar combinations for improving crop productivity, nutrient acquisition and energy efficiency in IndoGangetic plains.

Methodology : Field experiment was carried out involving two crop establishment practices [pigeonpea on ridges followed by $(f b)$ wheat on flatbed, and pigeonpea on raised-bed $f b$ wheat on raised-bed] and six combination of cultivars ( $3 \times 2$ ) of both pigeonpea (UPAS 120, ICP 67B and Pusa 992) and wheat (Shatabdi, Unnat Halna). The treatment effect was compared based on crop growth and yield, plant nutrient acquisition, system productivity and energy budgeting.

Results : Pigeonpea on raised-bed and wheat on flatbed had higher plant nutrient acquisition, above- and below-ground crop biomass and grain yield. Higher and significant correlations between plant nutrients uptake and grain yield indicated that crop establishment practices and cultivars had direct influence on plant nutrients acquisitions. UPAS 120 (pigeonpea) fb Unnat Halna (wheat) cultivar combination had the highest wheat equivalent yield (8.62 tha $\left.{ }^{-1}\right)$, net energy balance (192,667 MJ ha' ${ }^{-1}$ ) and energy ratio (5.88).

Interpretation : Thus, selection of suitable component crops cultivar and appropriate crop establishment practices would enable farmers to maximize the harvestable produce from pigeonpea-wheat rotation in Indo-Gangetic plains.

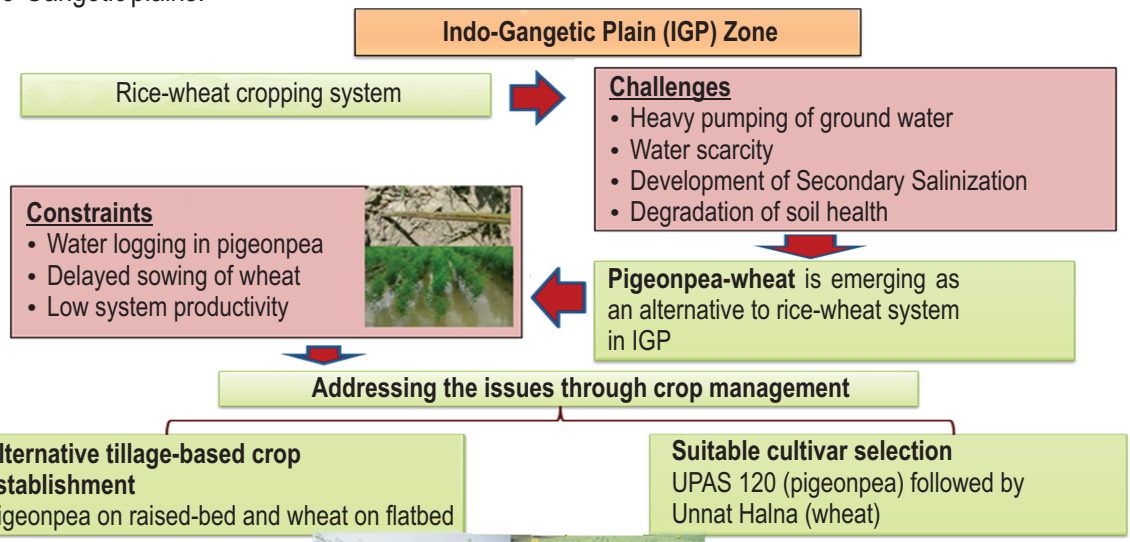

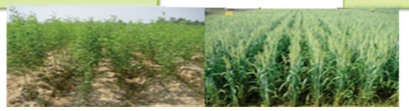




\section{Introduction}

Pigeonpea (Cajanus cajan L. Millsp)-wheat (Tritium aestivum L.) is an important cereal-legume rotation, mostly being practiced in the Indo-Gangetic plains (Singh and Ahlawat, 2007). The system is becoming popular over the traditional system of cereal-cereal (rice/maize-wheat) mainly due to reasons viz., low input requirement and high remuneration (profit). In addition, the system is soil fertility restorative in nature (as it builds up) and has higher input or resource use efficiency. Therefore, pigeonpea-wheat rotation is regularly being advocated to/adopted by farmers in the Indo-Gangetic plains as an alternative crop rotation to input-intensive and exhaustive cereal-cereal rotations (Singh and Ahlawat, 2007; Sepat et al., 2015; Ram et al., 2017). As a result of continuous cultivation of cereal-cereal rotations in Indo-Gangetic plains, particularly rice-based systems, has led to several negative effects on both soil and crop productivity such as degradation of soil health and declining factor productivity rendering nonviability and un-sustainability of the system. To reverse such illeffects concerning with the major cereal-based cropping systems, its diversification with introduction of pulses are being strategically promoted. Recently, following growing concern on depleting ground water resources and to control the advancement of secondary salinization through excess irrigation, there is an urgent need to replace the input intensive rice crop under rice/maize-wheat rotation of North-Western Indo-Gangetic plains with suitable short-duration pigeonpea during the rainy season (June-September) (Singh et al., 2005a). As the scope for introduction of such a soil building crop by including a legume like pigeonpea in lieu of prevailing rainy season cereals (mostly rice) is ample, it needs to bridge the research gaps both in terms of enhancing its productivity and up-scaling resource use efficiency. Thus, pigeonpea-wheat system will certainly act as a candidate crop rotation to be supported and promoted as one of the most efficient cropping systems in Indo-Gangetic plains in future (Singh and Ahlawat, 2006).

Despite having several advantages, the adoption of pigeonpea-wheat rotation by the farming community in IndoGangetic plains is rather slow due to management constraints resulting in lower system productivity and profitability (Singh et al., 2010). Since the promotion of pigeonpea-wheat rotation is limited to highland or medium-land agro-ecosystem because of the very upland habit of its kharif component (pigeonpea) (Singh et al., 2016), the choice of variety and management criteria vary accordingly. Under such a situation, short duration varieties of pigeonpea are most preferred. However, these short duration rainy-season pigeonpea cultivars are mostly susceptible to several diseases (including blight and wilt), especially when the field drainage is not satisfactory. As a result, the occurrence of phytophthora blight is high in such varieties of pigeonpea (Johansen et al., 2000). However, providing adequate field drainage and employing appropriate land configuration could be more useful even in low land situation for higher plant survival, better plant stand and higher productivity. In addition, since the targeted area for pigeonpea-wheat rotation is lowland rice-based ecosystem, appropriate land configuration (ridge, raised-bed, permanent raised-bed) and proper drainage could be morehandy and ought to be followed. To add further, growing of pigeonpea under such modified environment (elevated places either on the top of ridge or in line on raised beds) might offer more efficient utilization of applied water following improved drainage, reduced weed interaction and lodging, and up-scaling nutrient use efficiency (Fahong et al., 2004).

Under Indo-Gangetic plains condition, pigeonpea crop usually matures in the first fortnight of December resulting in delayed sowing of fall planted wheat causing plants to go for forced maturity and poor grain yield (Singh et al., 2005a). Field studies carried out in the Upper-Gangetic plains and TransGangetic plains amply demonstrates that delayed wheat sowing beyond normal sowing window (by $15^{\text {th }}$ November) may cause substantial yield loss in wheat at the rate of $50 \mathrm{~kg} \mathrm{ha}^{-1}$ day $^{-1}$ (Aggarwal et al., 2000). Therefore, suitability of short duration pigeonpea cultivar that matures in less then 120 days is one of the primary reasons for acceptability/ adoptability by poor farmers' of pigeonpea - wheat rotation in Indo-Gangetic plains.

Considering these facts, field experiments were conducted during two consecutive years (2013-2014 and 20142015) with the major objective to find out most efficient crop establishment practice and cultivar combinations for higher nutrient, energy and productivity in pigeonpea-wheat system.

\section{Materials and Methods}

Site characteristics : A field experiment was conducted for two consecutive years (2013-2014 and 2014-2015) on an Inceptisols (Typic Ustochrept) at new research centre of ICAR-Indian Institute of Pulses Research, Kanpur, India. The monthly mean annual maximum and minimum temperature of the experimental site are 33 and $20^{\circ} \mathrm{C}$, respectively. The average annual rainfall of the region was $722 \mathrm{~mm}$, and $\sim 75 \%$ of it is received during July to September through South-West monsoon. The daily weather variables during crop season are presented in Fig. 1. For the present investigation, different sites were used for $1^{\text {st }}(2013-2014)$ and $2^{\text {nd }}$ (2014-2015) year of experimentation for confirmation of the study eliminating site effects and carryover effects of cropping sequence, if any. The initial soil properties of two experimental sites are presented in Table 1.

Treatment details, experimental design and crop management : In the present investigation, two system based on crop establishment practices were evaluated in main plot viz., i) pigeonpea on ridge followed by wheat on flatbed and ii) pigeonpea on raised-bed $f b$ wheat on the same raised-bed. In pigeonpea, under ridge planting, ridges were made $50 \mathrm{~cm}$ apart with the help of a tractor drawn ridge-maker. Where, the raisedbeds were constructed with the help of a multi-crop bed planter maintaining a spacing of $1.0 \mathrm{~m}$ from centre to centre. Two rows of pigeonpea were sown on the top of the bed at a spacing of $50 \mathrm{~cm}$. 
During winter, after the harvest of pigeonpea, the main plot with ridges were tilled out and converted to a flat bed. Likewise, the main plots with raised-bed were also tilled out and again raised beds were made at $1.0 \mathrm{~m}$ apart (centre to centre) with the help of a multi-crop bed-planter. The dimension of each main plot thus, was $33 \mathrm{~m} \times 10 \mathrm{~m}$. During rainy season (for pigeonpea growing), each main plot was divided into three subplots wherein three pigeonpea cultivars (UPAS 120, ICP 67B and Pusa 992) were randomized. Following this lay-out for pigeonpea, 2 crop establishment practices $\times 3$ pigeonpea cultivars were statistically analyzed using a split-plot design. Again after harvest of pigeonpea, each sub-plot was again divided into two equal subsub plots and two wheat varieties (Shatabdi and Unnat Halna) were randomized in sub-sub plot. Therefore, for wheat crop, splitsplit plot was used for statistical analysis of the data. Wheat cultivars were sown after harvest of pigeonpea cultivars in the respective plots as different pigeonpea cultivars matured differently resulting in variable sowing datesin wheat.

Pigeonpea was fertilized with a uniform basal dose of $25 \mathrm{~kg}$ nitrogen, $26 \mathrm{~kg}$ phosphorus, $33 \mathrm{~kg}$ potassium, $20 \mathrm{~kg}$ sulphur and $5 \mathrm{~kg}$ zinc for one hectare. Likewise, the wheat crop was supplied with uniform dose of $120 \mathrm{~kg}$ nitrogen, $26 \mathrm{~kg}$ phosphorus, $33 \mathrm{~kg}$ potassium and $20 \mathrm{~kg}$ sulphur for one hectare. Both the crops were grown under assured irrigation. Need based plant protection measures were taken to control diseases and insect pests.

Measurement of growth and yield attributes : Five pigeonpea plants were sampled randomly from each plot at physiological maturity for taking observations on plant height, above ground dry biomass, root length, and root weight. For pigeonpea root studies, roots were dugout up to $100 \mathrm{~cm}$ soil depth from a $100 \mathrm{~cm} \times 100 \mathrm{~cm}$ area in each plot, washed thoroughly with tap water, soaked in antibiotic solution ( $30 \mathrm{mg}^{-1}$ chloramphenicol), ringed with distilled water. Likewise, for wheat crop, the plants of one $m$ row length were sampled from two locations in each plot for measurement of tiller density and effective tillers (tillers with spike). Meantime, observations like plant height, spike length, grains per spike and thousand grain weights were recorded from the sampled plants (20 plants). A net plot area of $30 \mathrm{~m}^{2}$ and $15 \mathrm{~m}^{2}$ were used for estimation of grain yield and straw/stover yields in pigeonpea and wheat, respectively. The harvested crop was sun-dried before recording its biomass and then threshed manually (in case of pigeonpea) or with a thresher in case of wheat (plot wise). The grain and stover/straw yield ( $t$ ha ${ }^{-1}$ ) was also recorded from each net plot after threshing. The stover yield was obtained after subtracting grain yield from total biomass yield (biological yield).

Chemical analysis of plant samples and estimation of nutrient uptake : Plant samples of pigeonpea and wheat were taken at harvest from each plot for chemical analysis. The samples were dried in an electric hot air oven at $65^{\circ} \mathrm{C}$ for $48 \mathrm{hrs}$ and then ground to powder using an electrical grinder. The ground plant samples $(0.5 \mathrm{~g})$ were digested with sulfuric acid for estimation of nitrogen by micro-Kjeldahl method and nitric acid: perchloric acid (10:4) to estimate phosphorus, potassium and sulphur concentration in grain and straw (Wolf, 1982). Total zinc was estimated by using Atomic Absorption Spectrometer (model GBC Avanta). Nitrogen was determined using FOSS Automatic nitrogen analyzer (FOSS, Sweden), total phosphorus with UV-VIS spectrophotometer (Shimadzu, Japan), and potassium in the digested material was determined using a flame photometer (Systronics, India). Nutrient uptake was estimated by multiplying the concentration (\%) of a particular nutrient of grain and straw/stover with their respective yield ( $\mathrm{kg} \mathrm{ha}^{-1}$ ) and finally the nutrient uptake by grain and straw was summed up to obtain total nutrient uptake.

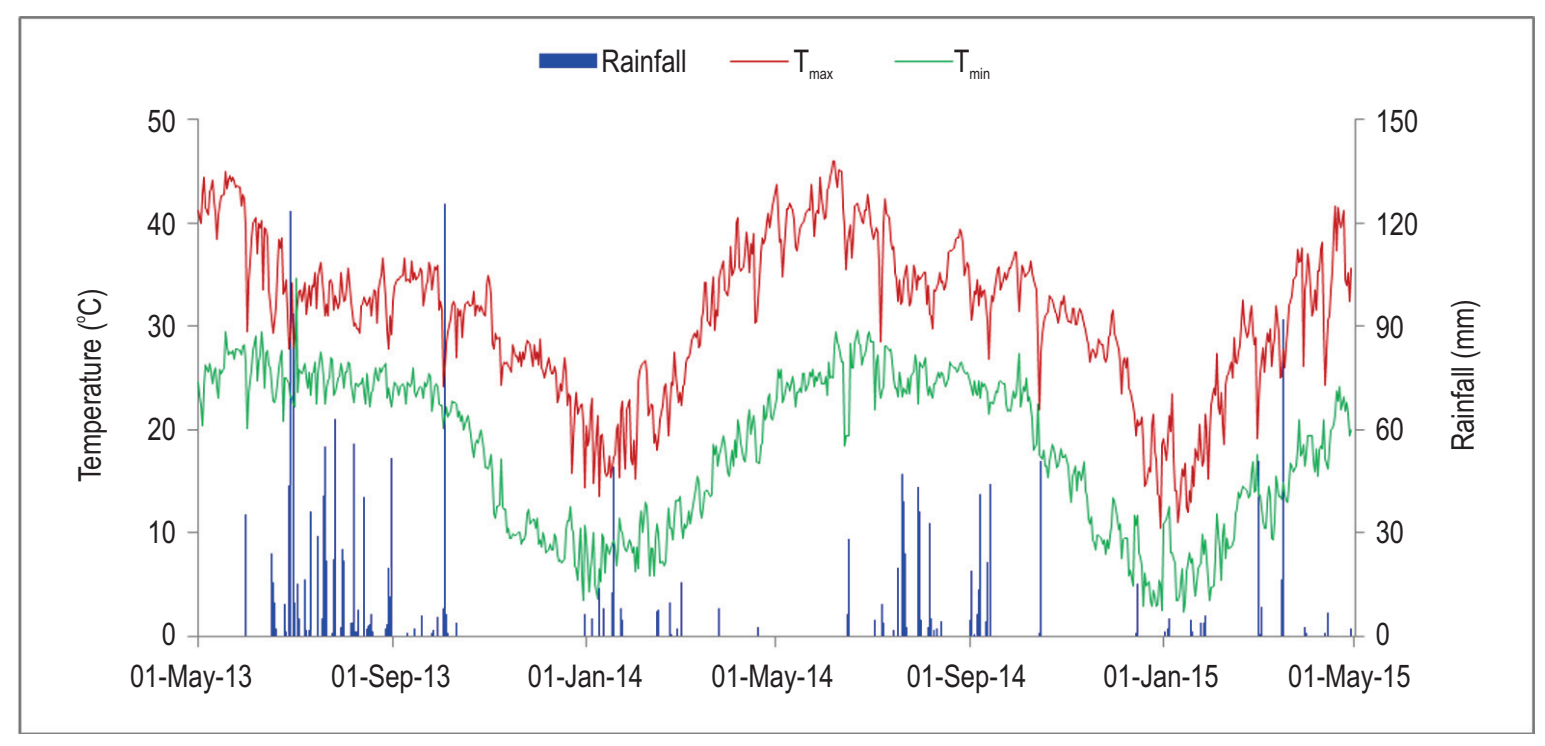

Fig.1 : Daily mean minimum and maximum temperatures and rainfall of the study site during 2013-2015 
Energy budgeting : All inputs and outputs (straw and grain yields) were used for evaluating energy relations. The energy coefficients from various available literature of each item were adopted to estimate input and output energy equivalents in terms of mega joules per hectare (MJ ha'). To explain the effect of treatment in terms of energy indices for pigeonpea and wheat, the assumptions as suggested by Mittal et al. (1985) were followed.

Statistical analysis : All the crop related data obtained from pigeonpea and wheat for consecutive two years were analyzed statistically using F-test, as per the procedure given by Gomez and Gomez (1984). LSD values at $p=0.05$ were used to determine the significance of difference between treatment means. The data were analyzed using online statistical software OPSTAT (Sheoran et al., 1998). The correlation values were determined using MS Excel 2007.

\section{Results and Discussion}

Crop growth, yield attributes and grain yield : Higher growth in pigeonpea was registered under raised-bed crop establishment practice as compared to ridge planting. Raised-bed method of crop establishment in pigeonpea crop also attribute towards growth attributes viz. total above ground dry weight $(18.7-20.6 \%)$, root length (18.9-20.6\%), root weight (18.8-18.9\%) when compared with ridge planting method of crop establishment (Table 2). In parallel to the growth attributes, raised-bed planting of pigeonpea also resulted in higher grain yield (11.5-11.8\%) as compared to ridge method of crop establishment. On the other hand, the study showed that pigeonpea cultivar significantly differed for growth attributes during both cropping seasons. Based on the studies on growth parameters, pigeonpea cultivars was found in the order of UPAS 120>Pusa 992>ICP 67B. On the same line, higher grain yield was recorded in UPAS 120 (1.38$\left.1.51 \mathrm{tha}^{-1}\right)$ which was closely followed by Pusa 992 and ICP 67B (0.91-1.01 tha ${ }^{-1}$ ) (Table 2).

In contrast to pigeonpea, wheat crop on raised-bed had no advantage on crop growth and yield attributes as wheat crop on flatbed had higher tillers density (12.4-15.3\%) over that in raised bed (Table 3). Likewise, higher effective tillers (12.1$12.2 \%)$, ear length (15.1-16.6\%), grains per spike (16.2-17.0\%) were also registered in flatbed sown wheat than those in raisedbed (Table 3). Nevertheless, the effect of crop establishment was found on par with regards to both plant height and thousand grain weight during both the years. In the present study, after pigeonpea Unnat Halna (suitable for late sown) of wheat cultivar was found to be more productive than Shatabdi (suitable for normal sown). Furthermore, the preceding pigeonpea cultivar also influenced grain yield of wheat; and wheat crop after pigeonpea cultivar UPAS 120 also had higher growth and yield attributes over those in remaining two pigeonpea cultivars (ICP 67B and Pusa 992).

In the present investigation, the performance of pigeonpea was also higher in raised-bed crop establishment than that on ridges alone. Increased growth and yield of pigeonpea in raised-bed method of crop establishment was mainly associated with increased root length and root weight; thereby indicating the fact that belowground crop growth of pigeonpea was mainly influenced by the raised-bed crop establishment. On the same line, pigeonpea on a raised-bed could be a better option compared to a flat bed ensuring optimum plant stand and increased crop productivity. Study conducted by Connor et al. (2003) in farmers' participatory trial in India also showed that bed planting was superior to flat planting in terms of realization of higher grain yield of pigeonpea. However, during heavy showers, beating action of rain drops even flattens these ridges leading in water stagnation, root exposure and ultimately poor plant growth (Singh et al., 2015a). Therefore, raised-bed planting of pigeonpea could be efficient to realize higher productivity in Indo-Gangetic plains.

In contrast to pigeonpea grown during rainy season, raised-bed crop establishment practice had no additional advantages over flat bed so farm crop growth, yield attributes and yield of wheat crop were concerned. Even grain yield of wheat under such modified land configuration (in raised bed) was marginally reduced as compared to flatbed. The results are in

Table 1 : Initial physico-chemical characteristics of the experimental soils $(0-0.2 \mathrm{~m})$

\begin{tabular}{llll}
\hline Parameter & \multicolumn{2}{c}{ Year of experimentation } & \\
\cline { 2 - 3 } & $\mathbf{2 0 1 3}$ & $\mathbf{2 0 1 4}$ & Methods used \\
\hline Soil texture & Sandy loam & Sandy loam & Bouyoucos hydrometer method (Singh et al., 2005) \\
$\mathrm{pH}(1: 2)$ & 8.39 & 8.37 & Glass electrode pH metre method (Jackson, 1973) \\
$\mathrm{EC}\left(\mathrm{dS} \mathrm{m} \mathrm{m}^{-1}\right.$ at $\left.25^{\circ} \mathrm{C}\right)$ & 0.28 & 0.26 & Conductivity bridge method (Richards, 1954) \\
Bulk density $\left(\mathrm{mg} \mathrm{m}^{-3}\right)$ & 1.47 & 1.46 & Core sampler method \\
Organic carbon $(\%)$ & 0.31 & 0.33 & Wet oxidation method (Walkley and Black, 1934) \\
Available- $\mathrm{N}\left(\mathrm{kg} \mathrm{ha}^{-1}\right)$ & 212.3 & 221.4 & Alkaline permanganate method (Subbiah and Asija, 1956) \\
Available-P $\left(\mathrm{kg} \mathrm{ha}^{-1}\right)$ & 14.8 & 15.2 & Olsen method (Olsen et al., 1954) \\
Available-K $\left(\mathrm{kg} \mathrm{ha}^{-1}\right)$ & 157.3 & 162.7 & Flame photometric method (Jackson, 1973) \\
Available-S $\left(\mathrm{kg} \mathrm{ha}^{-1}\right)$ & 10.6 & 12.8 & Turbidimetric method (Williams and Steinberg, 1959) \\
DTPA extractable-Zn $(\mathrm{ppm})$ & 0.42 & 0.49 & DTPA-extraction method (Lindsay and Norvell, 1978) \\
DTPA extractable-Fe $(\mathrm{ppm})$ & 2.86 & 3.11 & DTPA-extraction method (Lindsay and Norvell, 1978) \\
\hline
\end{tabular}




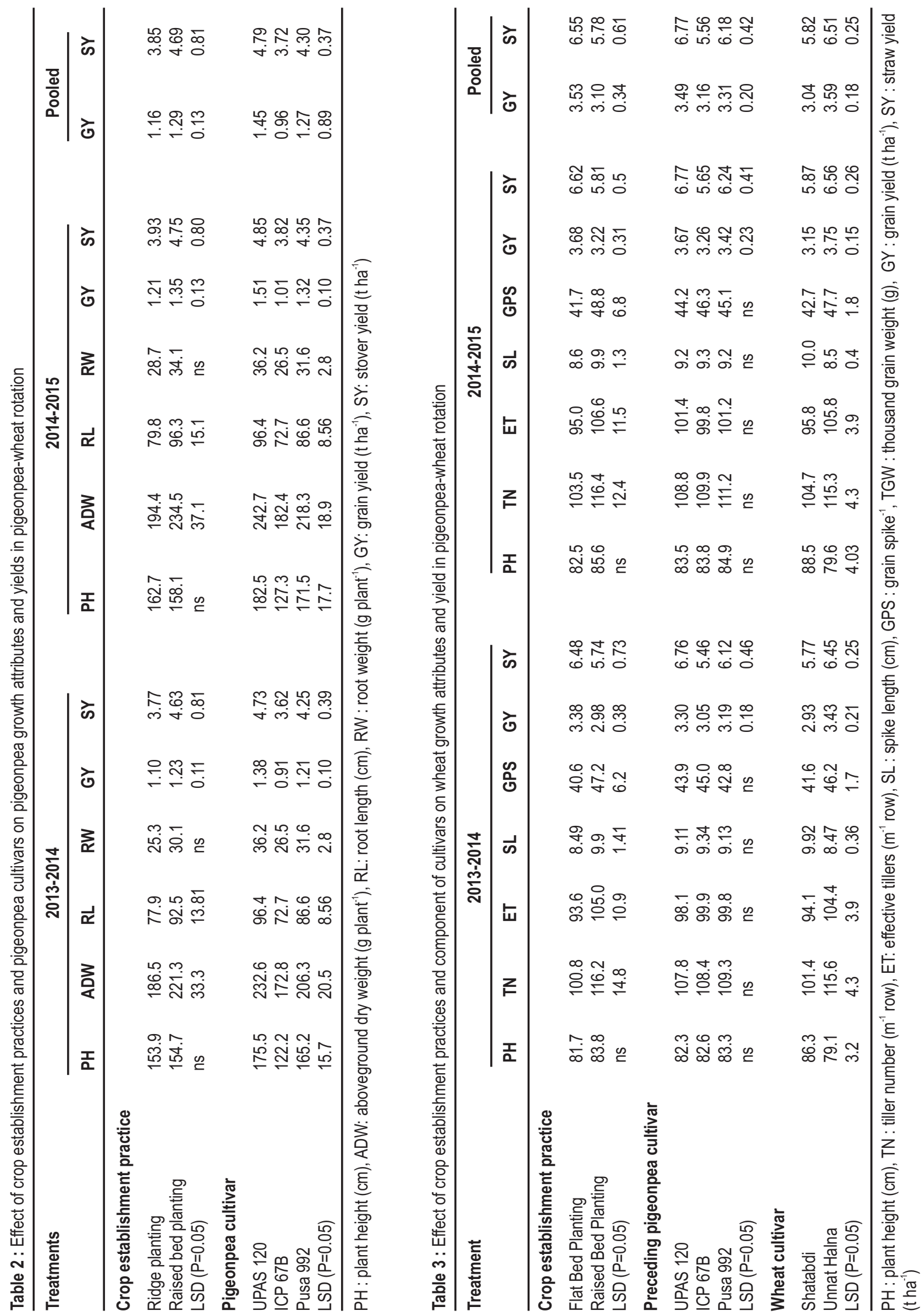



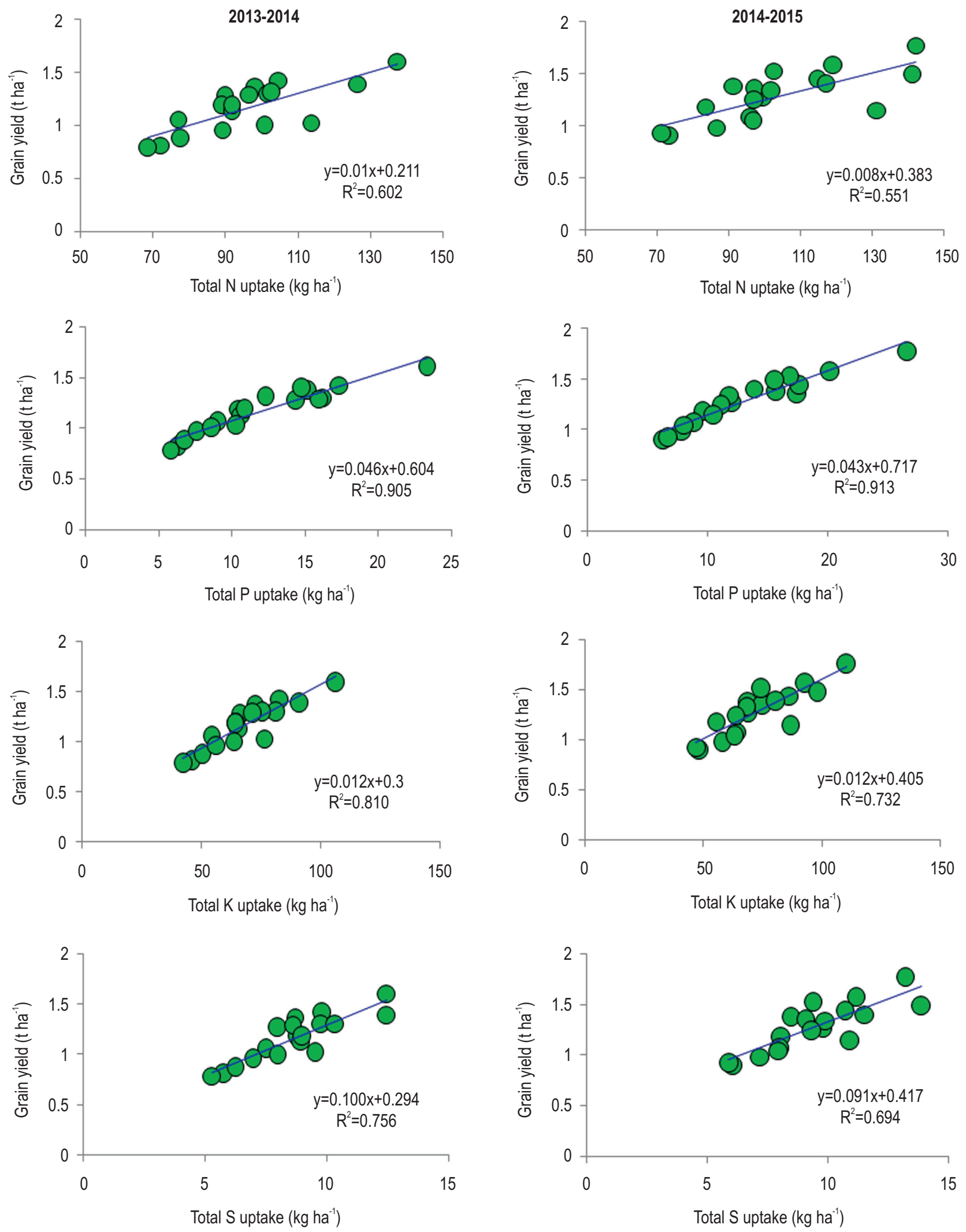

Fig. 2 : Correlations between total uptake of plant nutrients (N, P, K, and S) and grain yield of pigeonpea during 2013-2014 and 2014-2015 

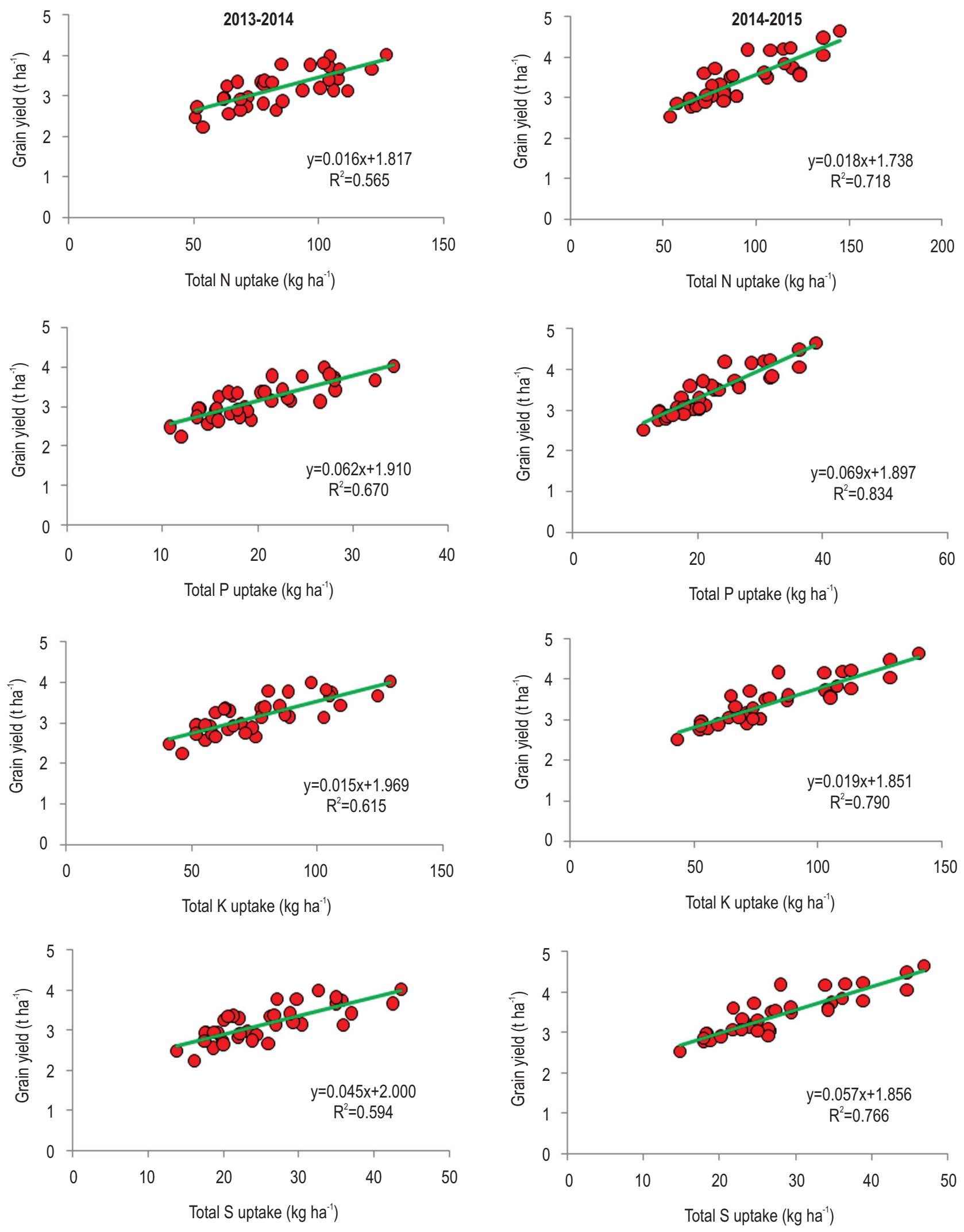

Fig. 3 : Correlations between total uptake of plant nutrients (N, P, K and S) and grain yield of wheat during 2013-2014 and 2014-2015 


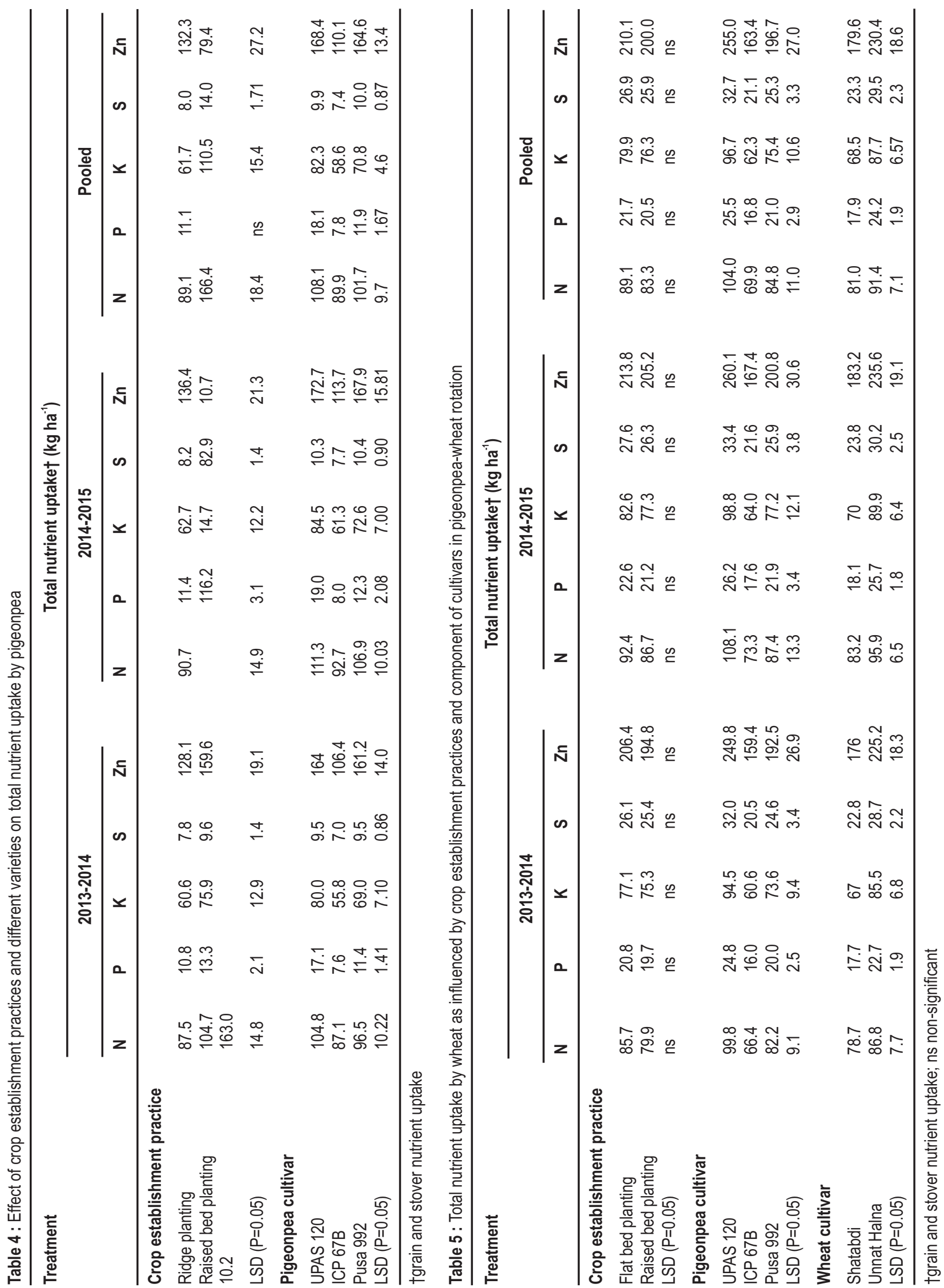


contradiction to the findings that have specified the advantage of raised-bed planting of wheat on crop productivity, water use efficiency, and nutrient acquisition in different agro-regions including Indo-Gangetic plains (Fahong et al., 2004; Jat et al., 2011). However, constrained by meagre rainfall (more evaporation) and agroecosystem/soil factor, the study conclusively indicated that raised-bed configuration for wheat might not be beneficial (on this sandy-loam soil). When the two systems-based crop establishment practices [i.e. ridge (pigeonpea) fb flatbed (wheat); raised bed (pigeonpea) fb raised bed (wheat)] were compared based on system productivity (WEY), both these systems were observed to be comparable. However, the study suggests that a strategic option viz., raisedbed (pigeonpea) fb flatbed (wheat) (not tested in the experiment) could be a more viable and alternative proposition for realizing higher productivities in pigeonpea-wheat rotation in northern Indo-Gangetic plains (mostly alluvial) soils (Singh et al., 2015; Ahlawat et al., 2005).

Among the cultivar combinations, WEY was found in the order of (UPAS $120 \mathrm{fb}$ Unnat Halna)>(UPAS $120 \mathrm{fb}$ Shatabdi) $>$ (Pusa $992 \mathrm{fb}$ Unnat Halna) $>$ (Pusa $992 \mathrm{fb}$ Shatabdi) $>$ (ICP 67B fb Unnat Halna)>(ICP 67B fb Shatabdi) (Fig. 4). Delayed maturity of pigeonpea leads to late sowing of wheat resulting in reduced grain yield (Singh et al., 2005a). Moreover, at later stages rapid increase in temperature towards the end of April in this zone causes forced maturity of late sown wheat (Aggarwal et al., 1994), making it difficult to compensate yield loss on one hand and resulting in under-utilization of applied inputs on the other. The present study also suggests that cultivar Unnat Halna is most suited for late sowing conditions, where grain yield of Shatabdi (suited for normal sown condition) did not perform satisfactorily under late sown condition. In addition, higher yield of wheat was registered after the pigeonpea cultivar UPAS 120 irrespective of wheat variety grown. This increased yield of wheat after UPAS 120 was possibly due to the higher leaf fall that could have contributed as source of plant nutrient for the successive wheat crop through partial decomposition in situ. As much of the nitrogen retained in the non-grain portion of the crop remains confined to green leaves containing about $4 \%$ nitrogen, defoliation and subsequent incorporation of these retained leaves at maturity may enhance the residual benefit to a subsequent cereal crop. Earlier studies underlined the significance of induced defoliation in pigeonpea imposed by foliar spray of $10 \%$ urea solution at physiological maturity in improving subsequent wheat yields, economizing fertilizer and augmenting SOC and mineral-nitrogen content (Chauhan et al., 2004).

Nutrient uptake and grain yield : Nutrient uptake data revealed that raised-bed method of crop establishment in pigeonpea enhanced plant nutrient acquisition from the study soil (Table 4). As compared to the pigeonpea crop on ridge, raised-bed crop establishment increased total uptake of nitrogen (19.6-28.1\%), phosphoras (23.1-28.9\%), potassium (25.2-32.2\%), sulphur (23.1-30.4), and zinc (21.9-24.5\%). This might be attributed to better crop establishment on raised bed over ridge planting, leading to higher nutrient acquisition. Pigeonpea cultivars viz., UPAS 120 and Pusa 992 also had higher uptake than that of cultivar ICP 67B and amongst the cultivars, UPAS 120 was found highly efficient in extracting soil phosphorus. In the present study, strong correlations $(r)$ exist between the pigeonpea grain yield and total nitrogen uptake $(0.74-0.78, P<0.001)$, total phosphorusuptake $(0.95-0.96 \mathrm{P}<0.001)$ total potassium-uptake $(0.86-0.90$, $\mathrm{P}<0.001$ ) total sulphur-uptake $(0.83-0.87, \mathrm{P}<0.001)$ (Fig. 2).

However, these variable crop establishment practices in wheat crop (flat bed and raised-bed) had no difference in total nutrient (N, P, K, S and Zn) uptake (by grain and straw) during both the years of study (Table 5). Wheat crop following different pigeonpea cultivars (UPAS 120, ICP 67B, and Pusa 992) in succession also showed marked variations in N, P, K, S and $\mathrm{Zn}$ uptake by both grain and straw (Table 5). The trend was also consistent for both the years. Wheat crop succeeding pigeonpea cultivar UPAS 120 had significantly higher uptake of N, P, K, S, and $\mathrm{Zn}$ in grain and straw. The average nutrient uptake data revealed that wheat crop preceding UPAS 120 facilitated N, P, K, S and Zn uptake to the tune of $22.6,16.4,29.7,27.0,22.6 \%$ and $22.3,26.8$, $27.3,30.0,34.4 \%$ by grain and straw, respectively, over the pigeonpea cultivar Pusa 992. Similarly, wheat cultivar Unnat Halna had higher nutrient uptake over that in Shatabdi. Like pigeonpea, strong correlations $(r)$ were found between wheat grain yield and total nitrogen-uptake $(0.75-0.85, P<0.001)$, total phosphorusuptake (0.82-0.91, $P<0.001)$, total potassium-uptake (0.78-0.89, $\mathrm{P}<0.001)$, and total sulphur-uptake (0.77-0.88, $\mathrm{P}<0.001)$ (Fig. 3).

Higher uptake of plant nutrients (N, P, K, S and Zn) under raised-bed method of crop establishment may be associated with higher crop growth and increased productivity of pigeonpea (Singh et al., 2010). Hence, our interpretation supports the fact that higher root vigour and biomass may have directly facilitated the higher acquisition of plant nutrients from soil under raised-bed crop establishment practice. In parallel with plant growth attributes, plant nutrient uptake of wheat under raised-bed was marginally lower than those in flatbed crop establishment practice. Higher uptake of nutrients under flat bed sown wheat was associated with greater biomass, grain yield and congenial microclimate received by the plants under flat bed. In contract to this, higher topography of raised bed (normally 20-30 cm) exposes the plant and soil surface for sunlight interception directly. The direct exposition of sunlight, especially towards furrow or outer rows of raised bed during hot summer (MarchApril) led to more evaporation of soil moisture leading to moisture deficiency to plants. Even little deficiency of moisture affects the root growth and thereby, acquisition of nutrient uptake from the soil (Fitter at al., 2002; Fageria et al., 2008).

In the present study, higher nutrient uptake in wheat crop after UPAS 120 also indicated the underlying fact that there was an enhanced plant nutrient acquisition in wheat crop. On the contrary, poor performance of ICP 67B was mainly associated with its low crop biomass and poor elasticity of crop. Further, the genetic makeup of ICP 67B is such that it has low 

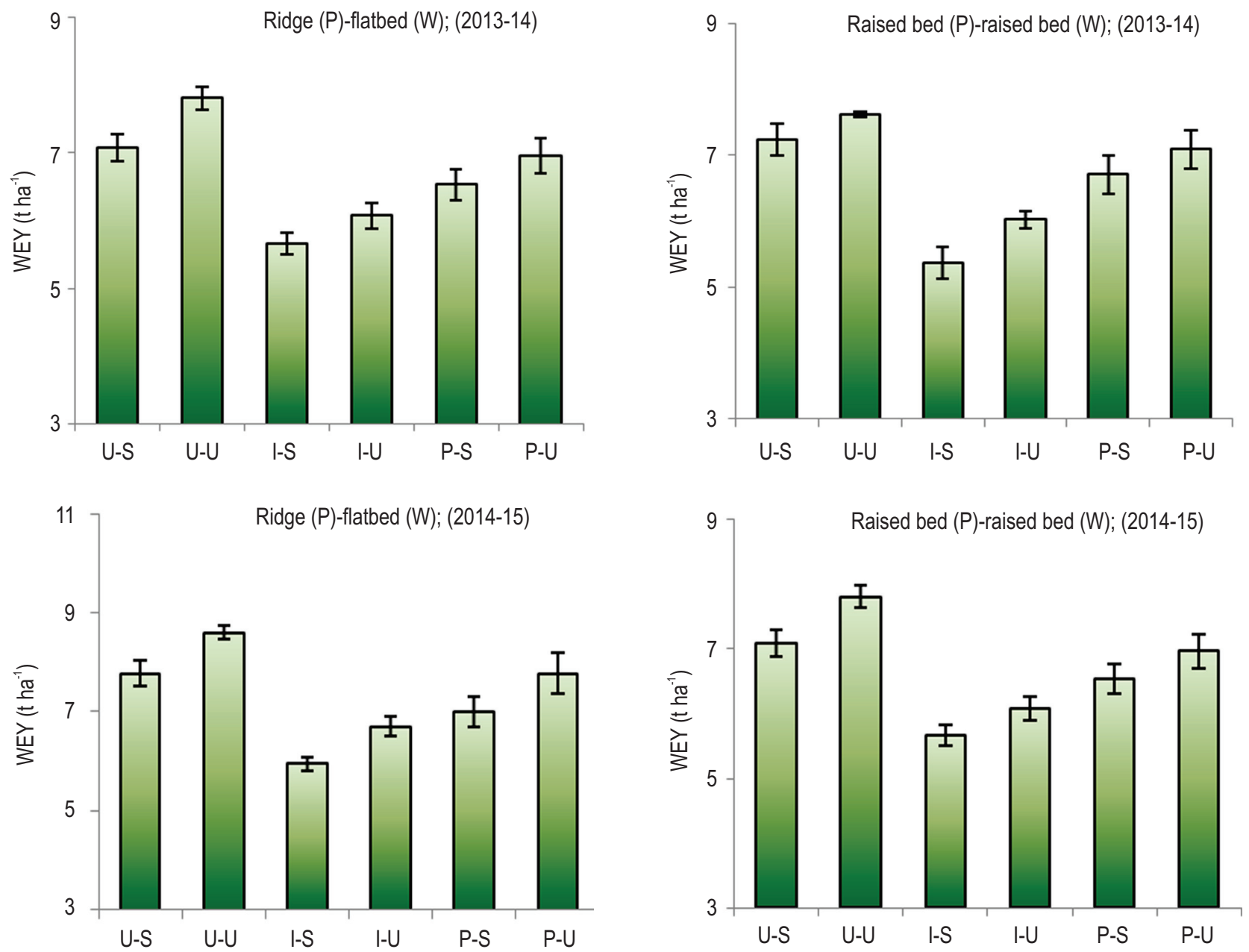

Fig. 4 : System productivity (wheat equivalent yield) under varying crop establishment practices in pigeonpea-wheat system. U-S: UPAS 120-Shatabdi, U-U: UPAS 120-Unnat halna, I-S: ICP 67B-Shatabdi, I-U: ICP 67B-Unnat Halna, P-S: Pusa 992-Shatabdi, P-U: Pusa 992-Unnat Halna

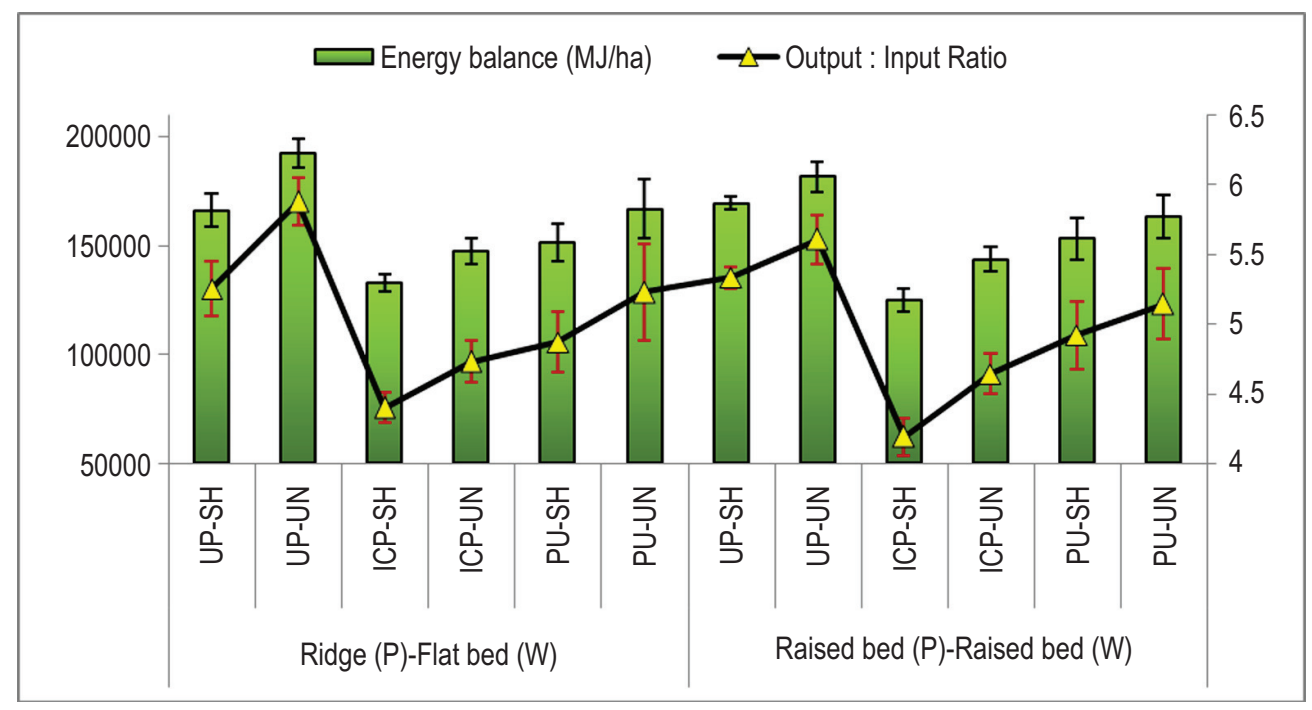

Fig. 5 : Energy budgeting under variable establishment practices and genotypes in pigeonpea-wheat system. UP-SH: UPAS 120-Shatabdi, UP-UN: UPAS 120-Unnat Halna, ICP-SH: ICP 67B-Shatabdi, ICP-UN: ICP 67B-Unnat Halna, PU-SH: Pusa 992-Shatabdi, PU-UN: Pusa 992 UnnatHalna 
foliage, branching and overall biomass. The plant spacing of this genotype was not effectively utilized and ground cover was also suboptimal for the cultivar ICP 67B. Higher nutrient uptake by wheat following Pigeonpea UPAS 120 (High biomass cultivar) might be due to addition of more organic carbon through leaf biomass. Moreover, leaf biomass is easily decomposable which increases the mineralizable nitrogen in soil (Basak etal., 2016).

System productivity and energy balance : The system productivity as estimated by wheat equivalent yield (WEY) was mostly preferred for comparison between the systems based on crop establishment practices (pigeonpea on ridge $f b$ wheat on flatbed and pigeonpea on raised-bed $f b$ wheat on raised-bed). The different cultivar combinations of pigeonpea and wheat largely varied with respect to WEY (Fig. 4). Similarly, wheat equivalent yield was found in decreasing order of (UPAS $120 \mathrm{fb}$ Unnat Halna)> (UPAS $120 \mathrm{fb}$ Shatabdi)>(Pusa $992 \mathrm{fb}$ Unnat Halna)>(Pusa $992 \mathrm{fb}$ Shatabdi)> (ICP 67B fb Unnat Halna)> (ICP 67B fb Shatabdi). Energy budgeting study also revealed that ridge (pigeonpea) fb flatbed (wheat) crop establishment had marginally higher energy balance than raised bed (pigeonpea) fb flatbed (wheat) (Fig. 5). Similar to system productivity, higher energy balance was apparent in UPAS120 fb Unnat Halna (192667 MJ ha-1), whereas the least was measured for ICP 67B fb Shatabdi (128904 MJ ha ${ }^{-1}$ ). A similar trend was also evident for the output: input energy ratio.

Higher productivity with sustainability remains the major concern of any crop planning. Any system which requires less input and contributes more is considered to be the efficient (Tuti et al., 2013). System productivity and energy balance data clearly illustrated that growing of UPAS 120 (pigeonpea) $f b$ Unnat Halna (wheat) and raised bed followed by flatbed could be the most remunerative and productive crop establishment and varietal module for pigeonpea-wheat rotation of Indo-Gangetic plains. Higher energy balance and output: input energy ratio in ridge (pigeonpea)-flatbed (wheat) was associated with higher grain and straw yield of wheat in flatbed and low energy use in tillage based crop establishment practice as compared to raised-bed (pigeonpea)-raised-bed (wheat). Moreover, higher energy balance of cultivar combination UPAS 120 (pigeonpea) fb Unnat Halna (wheat) was directly associated with higher energy output in the form of grain and straw yield of both pigeonpea and wheat cultivars.

Thus, based on the findings it may be concluded that sowing of pigeonpea (UPAS-120) on raised bed fb wheat (Unnat Halna) on flat bed can enhance system productivity, nutrient acquisition and energy productivity in Indo-Gangetic plains.

\section{Acknowledgment}

We acknowledge the encouragement and facilities provided for the field and laboratory studies by Director, ICARIndian Institute of Pulses Research, Kanpur, Uttar Pradesh, India.

\section{References}

Aggarwal, P.K., N. Kalra, A.K. Singh and S.K. Sinha: Analyzing the limitations set by climatic factors, genotype, water and nitrogen availability on productivity of wheat I. The model description, parametrization and validation. Field Crops Res., 38, 73-91 (1994).

Aggarwal, P.K., K.K. Talukdar and R.K. Mall: Potential yield of rice-wheat system in the Indo-Gangetic plains of India. Rice-Wheat Consortium Paper Series 10, Rice-wheat Consortium for the IndoGangetic plains, New Delhi, India (2000).

Ahlawat, I.P.S., B. Gangaiah and I.P. Singh: Pigeonpea (Cajanus cajan) research in India : An overview. Indian J. Agric. Sci., 75, 309-320 (2005).

Basak, N., A. Datta, T. Mitran, B. Mandal and P.K. Mani: Impact of organic and mineral inputs onto soil biological and metabolic activities under a long-term rice-wheat cropping system in subtropical Indian Inceptisols. J. Environ. Biol., 37, 83-89 (2016).

Chauhan, Y.S., A. Apphun, V.K. Singh and B.S. Dwivedi: Foliar sprays of concentrated urea at maturity of pigeonpea to induce defoliation and increase its residual benefit to wheat. Field Crops Res., 89, $17-$ 25 (2004).

Connor, D.J., R.K. Gupta, P.R. Hobbs and K.D. Sayre: Bed planting in rice-wheat system. Addressing resource conservation issues in rice-wheat systems of South Asia: A resource book. Rice-wheat consortium for the Indo-Gangetic Plains. Intl. Maize and Wheat Impr. Cent., New Delhi, India, pp.103-108 (2003).

Fageria, N.K., V.C. Baligar and Y.C. Li: The role of nutrient efficient plants in improving crop yields in the twenty first century. J. Plant Nutri., 31,1121-1157(2008).

Fahong, W., W. Xuqing and K. Sayre: Comparison of conventional, flood irrigated, flat planting with furrow irrigated, raised bed planting for winter wheat in China. Field Crops Res., 87, 35-42 (2004).

Fitter, A.H.: Characteristics and functions of root systems. In: Plant Roots: The Hidden Half (Eds.: Y. Waisel, A. Eshel and U. Kafkafi). Marcel Dekker, Inc., New York, pp. 249-259 (2002).

Gomez, K.A. and A.A. Gomez: Statistical Procedures for Agricultural Research. $2^{\text {nd }}$ Edn., John Wiley and Sons, Singapore (1984).

Jackson, M.L.: Soil Chemical Analysis. Prentice Hall of India. Pvt. Ltd., New Delhi (1973).

Jat, M.L., R. Gupta, Y.S. Saharawat and R. Khosla: Layering precision land leveling and furrow irrigated raised bed planting: Productivity and input use efficiency of irrigated bread wheat in Indo-Gangetic Plains. Am. J. Plant Sci., 2, 578-588 (2011).doi: 10.4236/ ajps. 2011.24069.

Johansen, C., M. Ali, C.L.L. Gowada, A. Ramakrishna, S.N. Nigam and Y.S. Chauhan: Regional opportunities for warm season grain legumes in the Indo-Gangetic Plain. In: Legumes in Rice and Wheat Cropping Systems of the Indo-Gangetic Plain-Constraints and Opportunities (Eds.: C. Johansen, J.M. Duxbury, S.M. Virmani, C.L.L. Gowda, S. Pande and P.K. Joshi). International Crops Research Institute for the Semi Arid Tropics/Cornell University, Patancheru, India/lthaca, New York, USA. p. 185-199 (2000).

Lindsay, W.I. and W.A. Norvell: Development of DTPA (Diethylenetriamine-penta-acetate) soil test for zinc, iron, manganese and copper. Soil Sci. Soc. Am. J., 42, 421-448 (1978).

Mittal, V.K., J.P. Mittal and K.C. Dhavan: Research digest on energy requirements in agricultural sector. Coordinating cell, AICRP on energy requirements in agricultural sector. Punjab Agricultural University, Ludhiana (1985).

Olsen, S.R., C.V. Cole, F.S. Watanabe and L.A. Dean: Estimation of available phosphorus in soils by extraction with sodium bicarbonate. USDACircular 939. USDA, Washington, DC, USA(1954). 
Ram., A.,D. Kumar, S. Babu, D. Prasad and I. Dev: Effect of sulphur on soil biological properties, residual fertility and yield of aerobic rice grown under aerobic rice-wheat cropping system in Inceptisols. J. Environ. Biol., 38, 587-593 (2017).

Richards, L.A.: Diagnosis and improvement of saline and alkali soils, United States Salinity Laboratory Staff. USDA Hand Book No. 60, p. 160 (1954).

Sepat, S., A.R. Sharma, D. Kumar and T.K. Das: Effect of conservation agriculture practices on productivity and sustainability of pigeonpea (Cajanus cajan)-wheat (Triticum aestivum) cropping system in Indo-Gangetic plains of India. Indian J. Agric. Sci., 85, 212-6 (2015).

Sheoran, O.P., D.S. Tonk, L.S. Kaushik, R.C. Hasija and R.S. Pannu: Statistical Software Package for Agricultural Research Workers. In: Recent Advances in information theory, Statistics \& Computer Applications (Eds.: D.S. Hooda and R.C. Hasija). Department of Mathematics Statistics, CCS HAU, Hisar, pp. 139-143 (1998).

Singh, D., P.K. Chhonkar and B.S. Dwivedi: Manual on soil, plant and water analysis. Westville Publishing House, New Delhi, pp. 16-20 (2005).

Singh, U. and I.P.S. Ahlawat: Productivity, nutrient uptake and soil fertility as influenced by phosphorus management in pigeonpea- wheat cropping system. Indian J. Agric. Sci., 76, 538-43 (2006).

Singh, U. and I.P.S. Ahlawat: Phosphorus management in pigeonpeawheat cropping system. Indian J. Agron., 52, 21-26 (2007).

Singh, U., C.S. Praharaj, S.S. Singh and N. Kumar: Influence of crop establishment practices and genotypes in pigeonpea-wheat system under Indo-Gangetic plains of India. J. Food Leg., 28, 315319 (2015).

Singh, V.K., B.S. Dwivedi, A.K. Shukla, Y.S. Chauhan and R.L. Yadav: Diversification of rice with pigeonpea in a rice-wheat cropping system on a Typic Ustochrept : effect on soil fertility, yield and nutrient use efficiency. Field Crops Res., 92, 85-105 (2005a).

Singh, V.K., B.S. Dwivedi, A.K. Shukla and R.P. Mishra: Permanent raised bed planting of the pigeonpea-wheat system on a Typic Ustochrept : effects on soil fertility, yield, and water and nutrient use efficiencies. Field Crops Res., 116, 127-39 (2010).

Subbiah, B.C. and G.L. Asija: A rapid procedure for the estimation of available nitrogen in soils. Curr., Sci., 25, 259-260 (1956).

Tuti, M.D., D. Mahanta, R. Bhattacharyya, B.M. Pandey, J.K. Bisht and J.C. Bhatt: Productivity, economics and energetics of pigeonpea (Cajanus cajan)-based cropping systems in mid-hills of northwest Himalaya. Indian J. Agron., 58, 303-308 (2013).

Walkley, A.J. and I.A. Black: Estimation of soil organic carbon by the chromic acid titration method. Soil. Sci., 37, 29-38 (1934).

Williams, C.H. and A. Steinberg: Soil sulphur fractions as chemical indices of available sulphur in some Australian soils. Aust. J. Agric. Res., 10, 340-352 (1959).

Wolf, B.: A comprehensive system of leaf analyses and its use for diagnosing crop nutrient status. Comm. Soil Sci. Plant. Anal., 13, 1035-1059 (1982). 